\section{Acknowledgements}

We are grateful to the many psychiatrists working in the NE Thames Region who have cooperated with this study, and to Philip Melville at the Regional Health Authority for providing the data on total admissions.

\section{References}

DEAN, C. \& GADD, E. (1989) An inner city home treatment service for acute psychiatric patients. Psychiatric Bulletin. 13, 667-669.

HIRSCH, S. et al (1988) Psychiatric Beds and Resources: Factors Influencing Bed Use and Service Planning. Report of a Working Party of the Section for Social and Community Psychiatry of the Royal College of Psychiatrists. London Gaskell (Royal College of Psychiatrists).

HOLlander, D., TOBIANSKY, R. \& POWELl, R. (1990) Crisis in admission beds. British Medical Journal, 301,664
HoulT, J. (1986) Community care of the acutely mentally ill. British Journal of Psychiatry, 149, 137-144.

Patrick, M., Higgrt, A., Holloway, F. \& Silverman, M. (1989) Changes in an inner city psychiatric inpatient service following bed losses: a follow-up of the East Lambeth 1986 survey. Health Trends, 21, 121-123.

STEIN, L.I. \& TEST, M.A. (1986) Alternatives to mental hospital treatment. I. Conceptual model, treatment program and clinical evaluation. Archives of General Psychiatry. 37, 392-397.

YATES. J. (1982) Hospital Beds. London: Heinemann.

D. Hollander, Consultant Psychiatrist, Community Mental Health, Bloomsbury \& Islington Health Authority, Whittington Hospital, Highgate Hill, London N19 5NF; and *M.S. Slater, Senior Registrar in Psychiatry. The Royal London Hospital, Whitechapel Road, London E1 1BB

*Correspondence

\title{
'Elderly graduates' and a hospital closure programme
}

\author{
Frank Holloway, Joan Rutherford, Jerome Carson and Lynda Dunn
}

\begin{abstract}
A sample of 49 'elderty graduate' residents of a hosplial designated for closure were surveyed in 1987 and followed up five years later. Twenty-two patients (45\%) had died: the mortality rate was much lower than that predicted by the regional health authority and approximated to that of the general population. All but one of the survivors was llving in supported accommodation at the time of follow-up. The majortty were satistied with the move and were recelving an appropriate level of care. However there was significant unmet need for structured activities and companionship. During the follow-up period the survivors had declined in functioning.
\end{abstract}

The programme of mental hospital closure that began in Britain during the 1980s is gathering momentum. There have been a number of detailed studies of the process and outcome of closure, notably the work of the TAPS researchers investigating the Friern and Claybury closures. However relatively little attention has been paid to the fate of the so-called 'elderly graduates', people admitted to the long-stay hospitals before the age of 65 who have grown old within the hospital. This is surprising since a majority of the functionally mentally ill residents of these hospitals is over 65 years of age (Clifford et al, 1991).

This paper reports a five year follow-up of a sample of 49 'elderly graduates' who were first surveyed in 1987 at Cane Hill Hospital, Coulsdon. Cane Hill was a large mental illness hospital which was planned to close in 1992. The sample represented the long-stay population of the hospital aged over 65 years managed by the Camberwell Resettlement Team (CRT), a multidisciplinary team responsible for the planning and implementation of successor services for one of the three health authorities involved in the closure. CRT members had specialist interest and expertise in long-term functional mental illness. Planning for elderly patients with dementia was undertaken by the Camberwell Old Age Psychiatry service. The aims of the study were to identify the clinical characteristics of the 'elderly graduate' population and to evaluate the outcome of the closure process in terms of the mortality, disability, quality of life and satisfaction with care of hospital residents. 
Table 1. Projected mortality rates

\begin{tabular}{lll}
\hline & Age & Mortallty rates \\
\hline South East Thames RHA & $60-69$ yrs & 0.0827 \\
& $70-79$ yrs & 0.1664 \\
& $80+y r s$ & 0.3953 \\
General population & $65-74$ yrs & 0.03 \\
& $75-84$ yrs & 0.08 \\
& $85+y r s$ & 0.2 \\
\hline
\end{tabular}

'Elderly graduate' residents who were the responsibility of the CRT and left Cane Hill went to five types of setting: a supported housing service (SHS) run by a voluntary organisation (with clinical support from the CRT), which provided a network of five bedroomed staffed houses; private sector residential homes (RHs); private sector nursing homes (NHs); purchased beds in another NHS hospital; and a hospitalhostel (HH). A previous paper reported the outcome of a three year follow-up of the elderly graduate' sample, prior to the closure of Cane Hill (Holloway, 1991). The Private Placements Service vetted RHs and NHs, prepared patients for the move out of hospital and continues to monitor the placements. Patients moved out of the hospital between 1987 and 1991 and all had left Cane Hill more than a year before the follow-up study.

\section{The study}

The 'administrative outcome' for the sample was ascertained from CRT records. The mortality rate for the sample was compared with projections produced by South East Thames Regional Health Authority, derived from national data on mortality within mental hospitals, and data on death rates in the population as a whole (see Table 1). For those who remained alive at five year followup, the patients' level of disability was assessed using the CAPE Behaviour Rating Scale (BRS) (Pattie \& Gilleard, 1979). The York Quality of Life Profile (Jones, 1985) was used to measure the extent to which patients' basic needs in ten domains were being met within their living setting. Data for these schedules were gathered from a key informant. In addition, all patients were approached to complete a satisfaction questionnaire, which elicited views about the setting which the patient currently lived in and their attitudes towards Cane Hill.

Data from the study were entered into an SPSSx-PC file. Comparisons between settings and over time were made using $t$-tests and ANOVA as appropriate.

\section{Findings}

\section{'Administrative outcome'}

Of the 1987 sample of 49 'elderly graduates', 13 died in Cane Hill, nine died following discharge and 27 were alive at five year follow-up. Eight patients moved to the SHS, a network of wellstaffed small houses within Camberwell run by a voluntary organisation. Thirteen patients moved into residential homes and nine moved into nursing homes. A further five patients moved into beds purchased in a long-stay NHS hospital. In addition, one patient moved into a hospitalhostel in Camberwell. Only nine out of 36 (25\%) discharged 'elderly graduates' returned to facilities within the catchment area.

There were no placement failures and no psychiatric hospital admissions among those discharged from hospital. One man was moved to another $\mathrm{NH}$ because the first home was unable to meet his needs adequately. During the follow-up period only one patient moved to another type of setting: one very well-functioning woman moved from the SHS to live with her sister. She was the only one of the 27 survivors at follow-up on whom data could not be obtained.

\section{Mortality}

At five year follow-up, 27 of the initial 49 patients were alive (55\%). A projection based on agespecific mortality rates for mental illness hospitals suggested that there would be 15 survivors (30\%). General population mortality rates predicted 33 survivors $(67 \%)$. The nine deaths among the 36 patients who left Cane Hill were distributed as follows: one (out of eight residents) within the SHS; six (out of 13 residents) in RHs; and two (out of nine residents) in NHs. The apparently high mortality rate among patients moving to RHs can be explained by the age structure of the population moving to RHs compared with those moving into other settings. None of the five patients who were transferred to another hospital in 1991 died in the following year.

At the three year follow-up the 1987 CAPE BRS score significantly predicted death. This was not the case for the five-year follow-up (mean BRS score for those surviving 10.2 (s.d. 6.9), mean BRS score for those dying 11.3 (s.d. 7.4)). Those who died were older but not significantly so than the survivors (mean age in 1987 of those who died 79.2 years, mean age of survivors 76.3).

\section{Characteristics of survivors}

The mean age of the survivors at follow-up was 81.3 years. Although the residents of the SHS (mean 78.7 years), HH (77 years) and hospital (mean 78.4 years) were younger than those in 
RHs (mean 81.9 years) and NHs (mean 85.1 years) these differences were not statistically significant.

In common with other 'old long stay' populations, the majority of the sample suffered from schizophrenia (82\%). In addition $8 \%$ suffered from bipolar affective disorder, $6 \%$ from organic mental illnesses and $4 \%$ from neurotic illnesses.

The mean CAPE BRS score for the follow-up sample was 13.6 (CAPE Dependency Grade D: 'high dependency'). Analysis of CAPE Behaviour Rating Scale data provides a detailed picture of the functioning and behavioural problems of the survivors. The majority of the survivors required assistance in bathing or dressing $(81 \%)$, nearly half were incontinent of urine or faeces once or more a week (46\%) and almost all required supervision outside the home $(88 \%)$. Over half (54\%) were regularly awake at night, although only a minority (27\%) engaged in problematical behaviours at night. Problematical behaviours were commoner during the day (54\%) and a proportion were prone to hoard items (27\%). Very few of the sample $(8 \%)$ socialised readily with others and few (15\%) were able to keep themselves occupied in constructive activity.

There were significant differences in mean CAPE BRS scores between settings $(P=0.03)$, with the least dependent residents living in the SHS and RHs and the most dependent residents occupying purchased hospital beds. Predictably the mean BRS scores for the survivors increased between 1987 and 1992, reflecting the increasing dependency of the survivors (mean score 1987 10.6, mean score 1992 13.6, $P=0.03$ ).

\section{'Quality of life' and quality of care}

The York Quality of Life Profile provided an assessment of the extent of which the patients' needs were met in ten critical life domains that are particularly relevant to elderly people with a mental illness. In five areas needs were fully met for nearly all the sample: food (100\% fully met); residential stability $(96 \%)$; personal care $(88 \%)$; protection $(88 \%)$; and health care $(85 \%)$. The material environment was rated as homely and comfortable for $68 \%$ of the sample and adequate for the remaining $32 \%$, while only $20 \%$ had no living space that was not shared with others (all hospital residents). Needs were not commonly fully met in three linked life domains: occupation ( $11 \%$ fully met, $35 \%$ partially met); leisure activities ( $19 \%$ fully met; $58 \%$ partially met); and companionship (23\% fully met; $65 \%$ partially met).

The Quality of Life Profile can provide a total QOL score (for each item $0=$ needs fully met, $1=$ needs partly met and $2=$ needs unmet). There were significant differences in total $\mathrm{QOL}$ score between settings $(P=0.07)$ which favoured $\mathrm{RHs}$ and NHs. The most striking differences were in the quality of the physical environment and living space, which were rated as poorer for the SHS and the hospital, and failure to meet health care needs, which was a problem restricted to the SHS.

\section{Satisfaction}

Patients were interviewed to obtain their views about the hospital and their current living setting. To the question "How do you feel about the time you spent in hospital?" ten (36\%) replied positively, eight (31\%) negatively and eight (31\%) provided ambivalent or vague answers. Of the 21 patients who had left hospital, $12(57 \%)$ preferred living in the community to living in hospital, three patients (14\%) preferred the hospital and six $(29 \%)$ gave ambivalent or vague replies. Similarly only three out of 21 patients who had left the hospital expressed a desire to return to hospital (14\%), 12 (57\%) did not wish to return and the remaining six (29\%) gave ambivalent or vague replies.

\section{Comment}

These results provide encouragement to those who carried out the Cane Hill closure. There was no excess mortality among elderly patients caught up in the closure process, with mortality rates approximating more closely to the general population than the long-stay mental hospital population. Where residents could provide an opinion the majority preferred community living and did not wish to return to hospital, although a significant minority could not respond meaningfully to these questions.

The data from the Quality of Life Profile suggested that most patients' needs were adequately met within their new setting. However significant unmet need was identified in the provision of structured activities, leisure and companionship. The results of the BRS indicate that the patients had severe deficits in these areas, and it is of concern that the new services that were utilised could not meet these needs.

The most striking features of the surviving 'elderly graduates', that they are old, have agerelated problems and are becoming increasingly dependent, may be obvious and predictable. However it was not taken into account by those responsible for designing the local SHS and $\mathrm{HH}$ provision in Camberwell, which took in significant numbers of 'elderly graduates'. These services, designed for people with severe psychiatric rather than physical problems, now have to struggle with the needs for physical care. This apparent oversight was partly caused by a fallure to develop locally a specialist nursing home for the elderly functionally mentally ill, which had 
been part of the original closure plan (Holloway, 1991). In future reprovision programmes provision for the 'elderly graduates' (who have traditionally been rejected by old age psychiatry services) should perhaps be developed and run by old-age specialists.

This study found no evidence to suggest that the strategy of utilising private sector residential and nursing homes as a key component of the reprovision was unsatisfactory, although the residential homes had poor local amenities compared with the provision opened in Camberwell. These homes provided a good quality physical environment and adequate personal care for residents: deficiencies, notably in the provision of occupation and leisure, were shared with the local voluntary sector provision and the NHS hospital utilised in the closure. It may be that the careful initial screening of homes carried out by the Private Placements Services and its continued active involvement in the placements contributed to the positive outcome of the high risk strategy of reliance on the private sector.

Although a small local study it is probable that these findings have general relevance. First, the patient population within Cane Hill is representative of other large mental hospitals (Clifford et al, 1991). Second, the attitudinal data, which found many patients were positive about the hospital but most preferred life in the community, are consistent with other studies of long-stay patients relocated from hospital. Third, good outcome for patients relocated from a mental hospital into the private residential sector has been previously reported (Perkins et al, 1989): key factors for good outcome may be careful screening of homes, thorough preparation of residents for the move and ongoing monitoring of the placement. The study utilised simple but well-tried evaluative tools and was carried out as part of routine clinical practice: hopefully such simple monitoring will be incorporated in all future closure programmes.

\section{Acknowledgements}

Dr Walid Hamid and Susan Benbow, RMN assisted in the collection and analysis of the data.

\section{References}

Clifford, P., Charman, A., WebB, Y. \& Best, S. (1991) Planning for community care. Long-stay populations of hospitals scheduled for rundown or closure. British Journal of Psychiatry, 168, 190-196.

Holloway. F. (1991) Elderly graduates and a hospital closure programme: a comparison of patients who are discharged and those who remain in hospital. Psychiatric Bulletin. 16, 321-323.

JONES. K. (1985) After Hospital: a study of long-term psychtatric pattents in York. Department of Soctal Policy and Social Work, University of York.

PATtIE. A.H. \& GILLEARD. C.J. (1979) Manual of the Clifton Assessment Procedures for the Elderly (CAPE). Sevenoaks: Hodder \& Stoughton.

Perkins, R.E., King, S.A. \& Hollyman, J.A. (1989) Resettlement of old long-stay psychiatric patients: the use of the private sector. British Journal of Psychiatry. 186, 233-238.

Frank Holloway, Consultant Psychiatrist, Maudsley Hospital, Denmark Hill, London SE5 8AZ: Joan Rutherford. Consultant Psychiatrist, Ridgewood Centre, Frimley, Surrey GU16 5QE; Jerome Carson, Department of Psychology, Institute of Psychiatry, De Crespigny Park London SE5 8AF; and Lynda Dunn. Department of Psychology. Institute of Psychiatry 